\title{
HISTORIA RECIENTE DE LA UNIVERSIDAD DE ALCALÁ (CONTINUACIÓN)
}

\section{RECENT HISTORY OF THE UNIVERSITY OF ALCALA (CONTINUED)}

\author{
AUTORES \\ José Morilla Critz: Catedrático de Universidad, Area de Fundamentos de la \\ Economía \\ jose.morilla@aol.com
}

\section{CURRÍCULUM VITAE}

Profesor en la Facultad de Ciencias Económicas y Empresariales. Universidad de Alcalá.

\section{RESUMEN}

Creemos que por lo dicho en las páginas que anteceden está claro que una idea como la que expresa el título de este apartado tiene muchos legítimos acreedores, pero también se deriva que la misma no tuvo muchas oportunidades de definirse netamente en sus líneas de actuación hasta 1984 y, sobre todo, es manifiesto que no pudo convertirse en un programa concreto de realizaciones más ambicioso que algunas recuperaciones aisladas.

\section{PALABRAS CLAVE}

Universidad - Alcalá - Historia 
We believe that what is said in the preceding pages it is clear that a notion like that expressed by the title of this section has many legitimate creditors, but also follows that it did not have many opportunities to clearly define its policy until 1984 and, above all, it is clear that there could be a specific agenda more ambitious realizations that some isolated recoveries.

\section{KEY WORDS}

University - Alcala - History

Como ya hemos mencionado, en algunas notas de Vivat Academia a las entregas anteriores de esta historia reciente de la Universidad de Alcalá, este texto publicado fue escrito por José Morilla en época tan lejana como 1989. En aquellos días él formaba parte del equipo de gobierno de la universidad, con el sempiterno rector Gala al frente. Razonable es, por tanto, que no haya querido profundizar demasiado en la historia del periodo comprendido entre 1984 y 1989, habiendo sido mucho más explícito con la historia anterior, ya que muchas de las ambiciones y proyectos de aquella comunidad universitaria habían sido traicionados, o lo estaban siendo por esas fechas.

Por todo ello, Vivat Academia ha solicitado al autor de estos textos que complete y continúe la historia, a la vez que se ha puesto en contacto con los protagonistas directos de la misma para que también contribuyan a darla a conocer. Sobre todo, echamos en falta una más precisa narración de los hechos ocurridos en el periodo constituyente, así como una relación de las personas que más directamente contribuyeron a la redacción de los Estatutos. 
Además, ya en este capítulo, y con mucha más razón en el que cerrará en el próximo número esta contribución de José Morilla, la redacción de la revista se vería obligada a insertar demasiadas notas aclaratorias, para dejar bien establecido cuál ha sido el devenir de nuestra institución y quiénes son los responsables más directos. Por consiguiente, hemos optado por no cargar demasiado estas páginas, a la espera de las próximas contribuciones de los diferentes protagonistas, que nos ilustrarán, con toda seguridad, sobre lo ocurrido desde 1979 con todo lujo de detalles.

\subsection{UN PROYECTO DE CIUDAD COMO CIUDAD UNIVERSITARIA RECUPERADA}

Creemos que por lo dicho en las páginas que anteceden está claro que una idea como la que expresa el título de este apartado tiene muchos legítimos acreedores, pero también se deriva que la misma no tuvo muchas oportunidades de definirse netamente en sus líneas de actuación hasta 1984 y, sobre todo, es manifiesto que no pudo convertirse en un programa concreto de realizaciones más ambicioso que algunas recuperaciones aisladas.

Para las instituciones y personas involucradas en el proceso de recuperación de la Universidad de Alcalá, el objetivo al que hubieron de dedicar todos sus esfuerzos hasta 1977 fue que la universidad "existiera" aunque fuera nominalmente en Alcalá. Y hasta 1984, las urgencias inmediatas, o la situación general de las Administración en plena transición política, convertían aquel posible objetivo en un simple ejercicio de erudita diletancia.

Pero creemos que ha quedado claro también que al haber estado el tema de la "recuperación universitaria de Alcalá de Henares" siempre como referente, se aprovecharon por los responsables de la Universidad en cada momento algunas circunstancias favorables, para que no solamente a los efectos de los símbolos y la liturgia, el pasado universitario de la ciudad le fuera útil a la nueva Universidad. Estuvieron los terrenos de la antigua base aérea, verdadera coartada de los 
sentimientos históricos de los ciudadanos de Alcalá, que permitió realmente que la Universidad volviera; y estuvieron los edificios del Colegio de Mínimos y de San Pedro y San Pablo, que empezaron a hacer presente la Universidad en la ciudad. Y estaban, naturalmente, las ideas expresadas por numerosas personas desde que en 1968 se comenzó a tener la esperanza de reinstaurar la Universidad de Alcalá de Henares y que hemos ido recogiendo a lo largo del trabajo. De ellas conviene ahora hacer una apretada síntesis:

- La primera fue la insistencia de la Sociedad de Condueños, ciertamente desde mucho antes de esa fecha, de que el patrimonio que había guardado celosamente debía destinarse, en la medida de los posible, a establecer de nuevo enseñanzas superiores.

- En 1967 la Universidad de Madrid pensó en emplear el Colegio de San Jerónimo para establecer enseñanzas de Filosofía y Letras en él, de acuerdo a lo que había sido su tradición.

- En 1968 Madariaga proponía reparar el grave error de haber abandonado la ciudad universitaria alcalaína y Eugenio Moreno Báez hablaba de la feliz oportunidad que se abría para restaurar una ciudad histórica de tanta raigambre.

- En 1969 un grupo de arquitectos de la Escuela de Diseño de Madrid se lamentaba, tras el fallido intento de la "Universidad Autónoma de Alcalá", de la oportunidad que habría habido de establecer un complejo de instalaciones universitarias aprovechando su conjunto histórico perfectamente adaptado a ello, situación única en el centro de España. 
- En 1972, ante una nueva esperanza de vuelta de la Universidad, el Ayuntamiento ofreció a la de Madrid no sólo las facilidades para instalarse en la base aérea, sino la de estar dispuesto a adquirir antiguas edificaciones para que aquélla se instalara en el casco histórico-universitario.

- En ese mismo año Luis Prados de la Plaza argumentaba en ABC a favor de una Alcalá universitaria, con la idea de recuperar un cuadro completo con el "rescate de los viejos edificios existentes que rivalizaron en saberes durante el Siglo de Oro con la Universidad de Salamanca".

- En 1974 estuvieron los informes de Felipe Calvo a la Junta de Gobierno de la Universidad de Madrid, pugnando por toda una "operación Alcalá", que incluyera la recuperación del conjunto urbano constituido por los antiguos edificios universitarios, que deberían ser recuperados dentro de un "Plan de ordenación urbana universitaria" y, particularmente, proponía la recuperación de la sede natural de la Universidad en el Colegio de San Ildefonso.

- En ese mismo año estuvo la proposición de la concejala de Cultura, Asela Sanz, de constituir dentro de la ciudad un museo cisneriano universitario.

- En 1979 estuvo la excelente decisión de la Dirección General de Arquitectura del M.O.P.U. de hacer una catalogación y una recuperación planimétrica, junto a propuestas de rehabilitación uso, de todos los edificios históricos de la ciudad, trabajo coordinado por el arquitecto Peridis.

Muchas otras iniciativas se podrían citar, pero basten ésas para ver que la idea de la recuperación de la Alcalá histórica como centro universitario fue un proceso acumulativo mediante el cual se convirtieron en una idea matriz natural que 
"estando en el ambiente" a comienzos de los años ochenta podía encontrar una situación propicia para dar lugar a un programa de actuación.

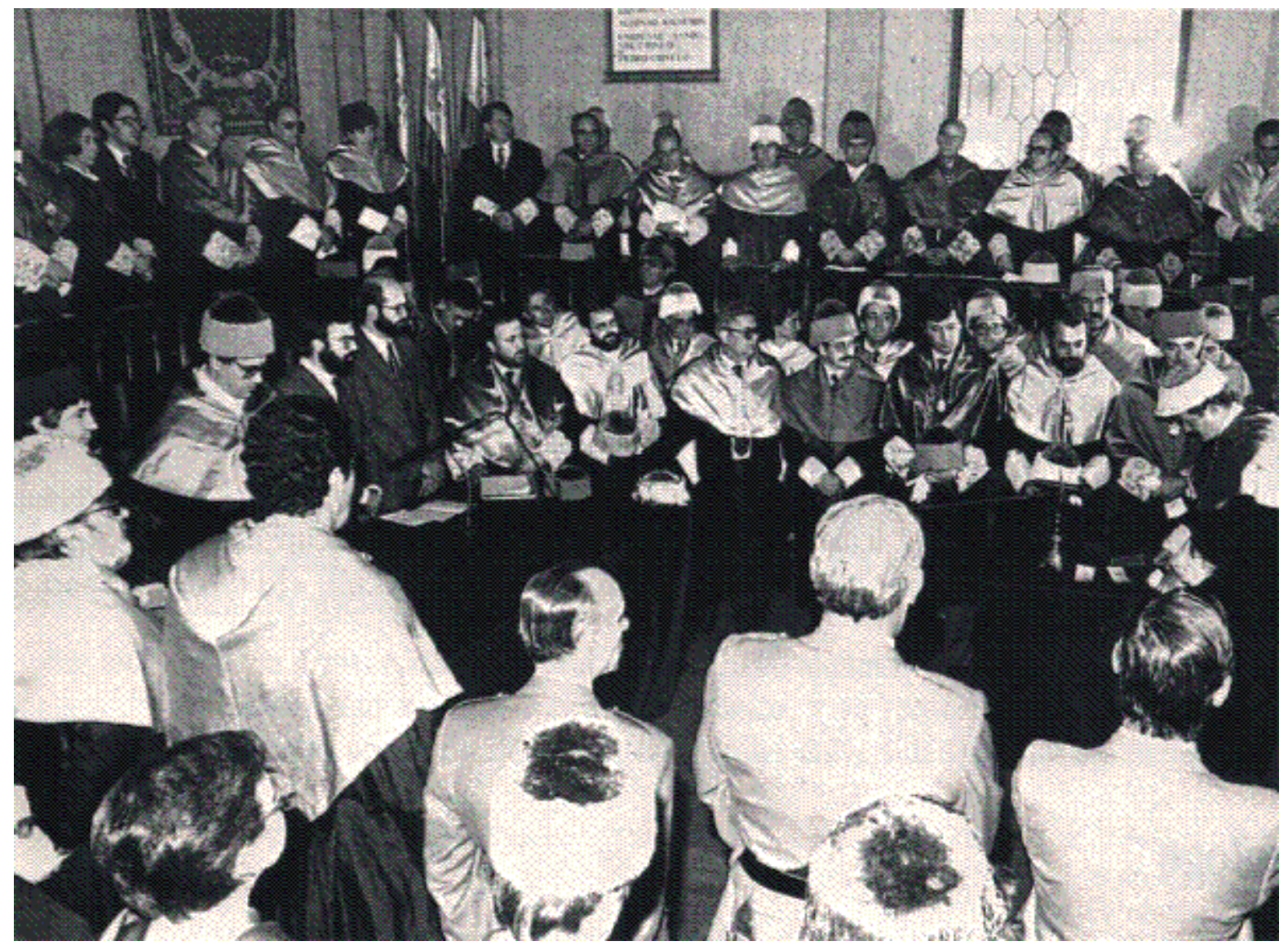

Inauguración del curso académico 1986/87.

Eso ocurrió, desde la ciudad, cuando equipos humanos nuevos llegaron al Ayuntamiento con aquellos programas de los que hablamos, tendentes a buscar alternativas a una Alcalá muy joven y dinámica pero sumida en ruinas antiguas y en fábricas nuevas que se abandonaban. Fruto de ello fue la necesidad que el Ayuntamiento, presidido por don Carlos Valenzuela, planteó a la Administración de realizar un "Plan de urgencia y salvación de Alcalá", que empezó a dar sus frutos no sólo por el inventario de edificaciones que ello obligaba a hacer y por introducir la idea de "recuperación de Alcalá" en diversos organismos de la Administración involucrados en la ciudad (Ministerios de Defensa, Justicia, Cultura, Ayuntamiento 
de Madrid y, una vez constituida, Comunidad de Madrid), sino que se empezaron a obtener compromisos limitados de rehabilitación pero concretos: capilla del Oidor, ruinas de Santa María, iglesias de los Caracciolos y del Carmen Calzado.

En el ambiente rehabilitador del patrimonio que ese plan había propiciado y la dimensión pública que fue alcanzando, algunos alcalaínos llegaron a formular líneas de actuación muy inteligentes en el campo universitario, como Santos Luciano, que en 1979 solicitaba la cesión de los edificios de prisiones para colegios mayores y la creación de un centro de estudios de Alcalá y su comarca con una extensa biblioteca, al tiempo que pedía consorcios Ayuntamiento-Universidad y empresas-Universidad, para vincular ésta a la ciudad.

El equipo municipal que, aparte del alcalde -procedente del Instituto Nacional de Administración Pública-, contaba para esas cuestiones con Arsenio Lope Huerta (que además de ser miembro activo de la Sociedad de Condueños, había estado en todos los frentes de lucha por la recuperación de la Universidad: Grupo 69 y Asociación de Amigos de la Universidad), tenía claro el tema cuando se ofreció la oportunidad, en ese mismo año de 1979, de adquirir los cuarteles que el Ejército se disponía a abandonar, decidiendo que habrían de destinarse a usos universitarios, recuperando así su inicial finalidad.

Arsenio Lope, en esa ocasión, consideraba también que la Universidad debía de recuperar su nombre antiguo, el Colegio de San Ildefonso y el resto de edificios que fueron universitarios, en concreto (aparte de los citados): Prisión Militar, cuartel de Mendigorría y Colegio de Málaga Nota39, aunque mostrara poca confianza de que desde dentro de la Universidad hubiera un gran deseo de arraigarse en la ciudad.

En los años que siguieron hasta 1983, con una ciudad que empezaba a tener sus semirruinosos edificios históricos más vacíos que nunca y, a la vez, la crisis económica de la ciudad no hacía sino crecer, la recuperación del patrimonio histórico para usos universitarios se convirtió en un tema ya no sólo urbanístico y cultural, sino económico, a cuyo debate el que escribe estas líneas aportó también sus ideas Nota40. Y así fue incorporado, sobre todo, a los programas políticos de las elecciones 
municipales de 1983, que habrían de colocar de alcalde a Arsenio Lope, uno de sus más conspicuos defensores.

Volviendo atrás, ya vimos cómo la Universidad de Alcalá había decidido durante su proceso constituyente ser una universidad arraigada en su entorno geográfico, histórico y económico, hasta tal punto que esta decisión la dejó plasmada en sus Estatutos Nota41, demostrando con ello que en los años anteriores se había formado la conciencia suficiente como para vislumbrar el potencial que llevaba en sí una identificación colectiva clara por un objetivo y, también, naturalmente, que en ese proceso constituyente había triunfado la idea de "universidad de área" que identificó al desde entonces su rector don Manuel Gala Nota42.

De este modo, en 1983 se daban, pues, muchas circunstancias favorables para plantear en Alcalá un plan integral de recuperación, con su centro de gravedad y su coartada en la Universidad. El problema podría estar en su viabilidad económica y en la capacidad organizativa y técnica para llevarlo adelante. Aquí fue cuando las necesidades de la Universidad y la crisis económica jugaron, dada también la visión práctica que de la situación tuvieron sus rectores, a favor de Alcalá en un momento que, tal vez, el tiempo juzgue como histórico.

En 1983 ya vimos cómo en la Universidad de Alcalá se había terminado "periodo de gracia" del limitado número de estudiantes con el que había vivido, en líneas generales, desde 1979. Ante la perspectiva de la pronta apertura de sus nuevos edificios, se había dejado crecer el número de facultades y de alumnos; pero esos edificios no iban a abrirse y, además, uno recién inaugurado (el de Filosofía y Letras en el Colegio de San Pedro Y San Pablo) resultó inmediatamente pequeño para su fin. Por otra parte la rehabilitación que se había hecho de la Facultad de Económicas amenazaba ruina. Para más problemas, la paralización que había habido en la urbanización del campusamenazaba con dejarlo sin accesos en cuestión de meses y también que ninguna nueva edificación pudiera entrar en funcionamiento ante la carencia de las infraestructuras de abastecimiento y servicios básicas. 
En otro orden de cosas, la crisis económica había llevado ya en 1983 a que se convinieran entre el Estado y los interlocutores sociales programas de inversión pública (como el "Acuerdo Nacional sobre el Empleo"), con los que diversos departamentos ministeriales -entre ellos el de Educación- contarían con créditos para inversiones adicionales. Y, también, sólo hace falta mencionar el carácter casi paradigmático que ya por esos años había adoptado en España la idea de "rehabilitación" del patrimonio histórico. Numerosos programas, sostenidos por la Administración nacional o por las autonómicas, pretendían unir las necesidades de dar empleo, reconvertir la mano de obra y dar satisfacción a la creciente sensibilidad ecológico-cultural del país Nota43.

Hasta cierto punto, la Administración estaba falta de proyectos que cumplieran esos requisitos y que, por su urgencia, justificaran un tratamiento particularizado a la hora de asumir compromisos firmes de financiación. El Rectorado de la Universidad de Alcalá había planteado sus agobios de infraestructura al Ministerio de Educación, cuya Dirección General de Inversiones contestó solicitando un "Plan general de necesidades de inversión en infraestructura" con una programación de su realización y una valoración económica.

El Rectorado vio claro que ésta podía ser la ocasión de llevar a cabo para la Universidad de Alcalá aquella planificación integral de primer establecimiento que siempre había faltado en su complicada historia de refundación y, por otra parte, las necesidades inmediatas eran tan evidentes, las ideas de futuro basadas en la recuperación del patrimonio histórico-universitario estaban tan en el ambiente de la ciudad y en el propio ideario constituyente de la Universidad y en el programa electoral del rector, que aquel "Plan General" fue elaborado en unas cuantas semanas.

Las necesidades estaban claras: Nota24 de VA

- Reiniciar la urbanización del campus, según los estudios hechos en la etapa del "Campus de la Complutense". 
- Acabar y equipar las facultades paralizadas.

- Construir dos bibliotecas "centrales": en el campus y en la ciudad.

- Acometer las obras de la Facultad de Derecho.

- Solventar las deficiencias arquitectónicas del edificio rehabilitado para Facultad de Ciencias Económicas y Empresariales.

- Ampliar las instalaciones de otras facultades.

- Adquirir y restaurar un nuevo edificio para la Facultad de Filosofía y Letras.

- Construir residencias para estudiantes en el casco antiguo.

- Construir instalaciones deportivas.

- Hacer una dotación inicial para equipamiento científico. Ampliar las instalaciones de Guadalajara.

La inversión necesaria para todo ello se estimaba en unos cinco mil millones de pesetas, a librar en cuatro años, y, como era lógico, en una situación en la que a efectos "oficiales" la Universidad de Alcalá estaba plenamente funcionando, el Ministerio se declaraba incapaz de asumir tan elevada financiación procedente de los fondos necesarios para todas las universidades, aunque el plan lo considerara necesario y realista.

Al mismo tiempo que estas gestiones se realizaban por la Universidad, el nuevo Ayuntamiento constituido tras las elecciones de 1983, aceleró las negociaciones con el Ministerio de Defensa para adquirir los cuarteles anteriormente mencionados y, bajo el lema "Recuperar Alcalá", que había defendido en su campaña electoral, el alcalde aceleró las negociaciones que con diferentes organismos (Ministerios de Cultura y Justicia, Comunidad de Madrid y Ayuntamiento de Madrid) estaban iniciadas para adquirir y/o restaurar parte del patrimonio histórico alcalaíno. En concreto: las iglesias de los conventos de Caracciolos y Carmen Calzado para auditorios, el convento de San Agustín para Juzgados -cuyas obras estaban paralizadas-, el de la Madre de Dios para Museo Arqueológico, el Colegio de Málaga y la restauración de los dos teatros históricos de la ciudad: el Cervantes y el Salón Cervantes. 
Los problemas ante los que se enfrentaba el Ayuntamiento para llevar adelante tamaña empresa eran los mismos que tenía la Universidad por su parte: conseguir de las instituciones correspondientes los compromisos de financiación necesarios. Además, había de mostrar, sobre todo ante el Ministerio de Cultura, que las rehabilitaciones de la ciudad complutense tenían una finalidad de uso concreto para vencer las reticencias formadas por la experiencia negativa de algunos programas en otras partes del país.

Ante la situación, podrían haberse planteado dos estrategias diferentes:

Actuar las dos instituciones separadamente, compitiendo en algunos casos por las inversiones necesarias.

Hacer de todo ello un plan de recuperación general y presentarlo al unísono ante las posibles instancias financiadoras.

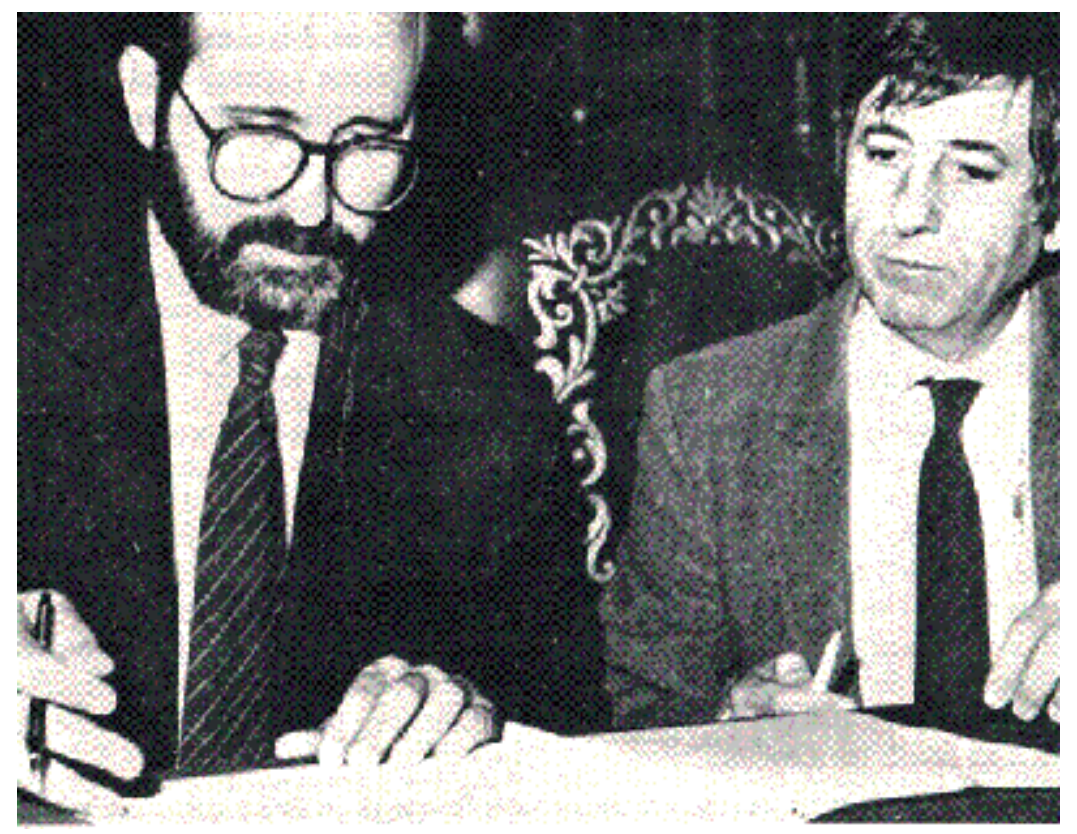

Cesión del Colegio de los Basilios. En la fotografía el alcalde don Arsenio Lope Huerta y el rector de la Universidad don Manuel Gala Muñoz

Era lógico, visto lo que ya hemos expuesto con anterioridad sobre la formación, tanto en la ciudad como en la Universidad, de un espíritu de recuperación de la Alcalá universitaria, que el Rectorado y el Ayuntamiento se unieran para actuar 
conjuntamente. Sus dos máximos representantes tuvieron entonces muy claro que era el momento propicio para presentar un plan lo suficientemente atractivo como para involucrar en él a numerosas ramas de la Administración y justificar una fuerte inversión en el mismo.

Las intenciones restauradoras de la ciudad necesitaban la coartada de las claras necesidades inmediatas de la Universidad, cuya potenciación era, por otra parte, una de las razones de ser de todo alcalaíno consciente de su historia. Y la Universidad necesitaba dar una coartada para conseguir una inversión extraordinaria en ella que podía ser la de que solucionando sus problemas se recuperaba, además, uno de los grandes patrimonios histórico-universitarios del país. En resumidas cuentas, en Alcalá se daban las condiciones óptimas para hacer una universidad y una ciudad con una clara vocación cultural, recuperando precisamente su patrimonio artístico.

La Universidad y el Ayuntamiento se pusieron muy pronto de acuerdo, alcanzando a firmar en Noviembre de 1984 un convenio en el que se recogían las líneas de actuación comunes Nota44. Algunas de ellas muestran palpablemente la identificación existente en torno a los objetivos, como aquellas en las que se acuerda por estrategia operativa que tres cuarteles que adquirirá el Ayuntamiento les sean vendidos a la Universidad con la financiación que ésta obtenga de una tercera parte, y en la que se decide crear una oficina conjunta de alojamientos para los universitarios.

En ese convenio estaba plasmado todo un plan de recuperación de buena parte del patrimonio histórico alcalaíno para destinarlo a hacer de Alcalá una auténtica y "diferente" ciudad universitaria, con residencias, centros culturales y viviendas universitarias diseminadas por la Alcalá histórica. Era hacer de todo el casco antiguo uncampus integrado en la vida ciudadana.

Pero, con todo, lo más importante fue la voluntad de actuar conjuntamente para unir ese plan y las demás necesidades de infraestructura universitaria y ciudadana y negociar coordinadamente entre sí ante otras instancias de la Administración para conseguir los compromisos de inversión necesarios. 
De este modo, la Universidad pudo responder al reto que le había lanzado el Ministerio de Educación de buscar otros socios entre la Administración para acompañarle en sus compromisos de inversión con esta "pequeña universidad". La Alcaldía y el Rectorado negociaron a lo largo de 1984 con cuatro Ministerios (Educación, Cultura; Obras Públicas y Justicia), la Comunidad Autónoma de Madrid y la Diputación de Guadalajara, la asunción de los compromisos de cesión, adquisición, construcción, rehabilitación y equipamiento necesarios para la "adecuada dotación de infraestructura de la Universidad y el equipamiento cultural de Alcalá de Henares", que quedó plasmado en un convenio muy preciso, cerrado en diciembre de ese año nota45.

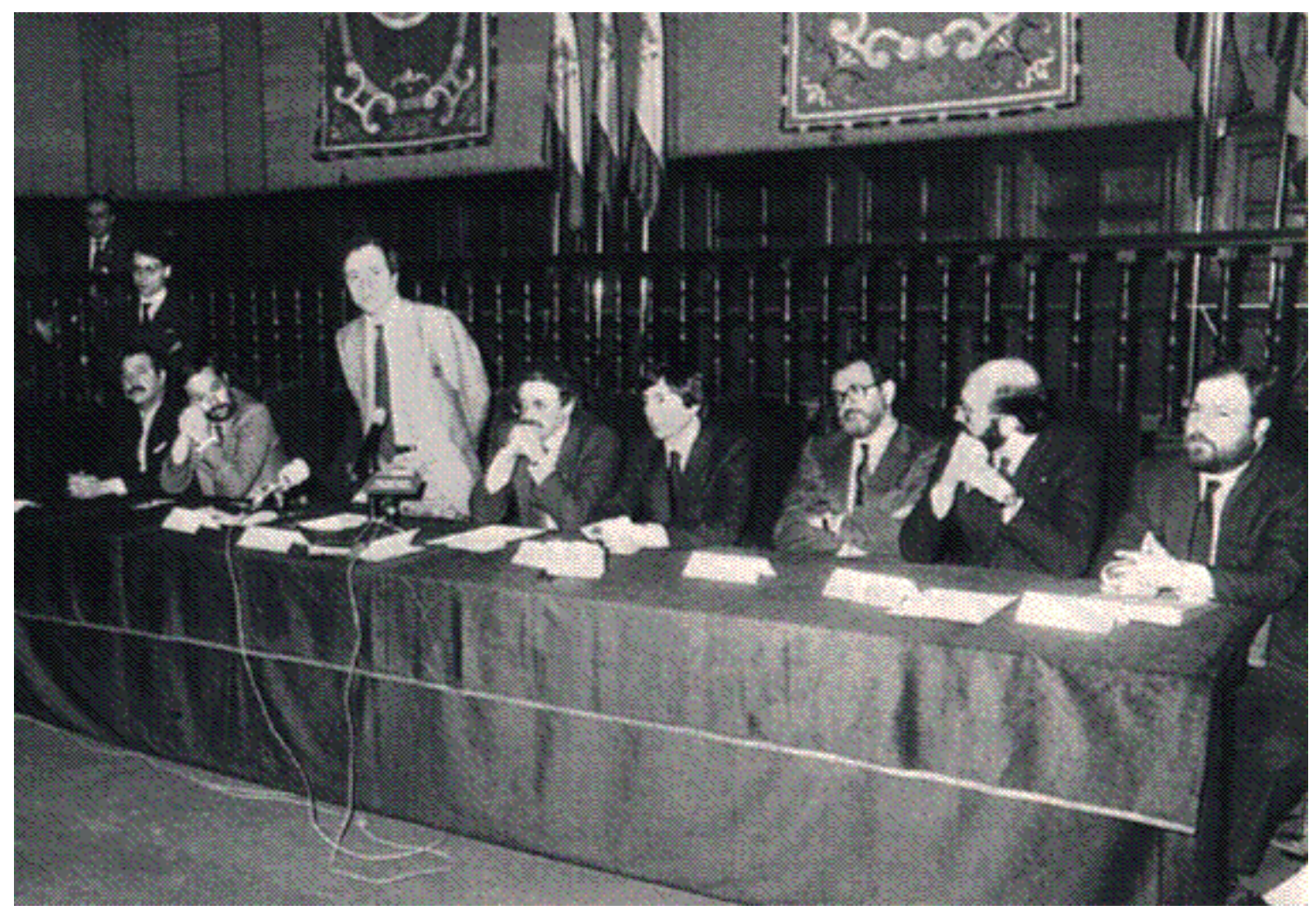

Firma del convenio interdepartamental, enero, 1985. De izquierda a derecha: don José Tomey, presidente de la Diputación de Guadalajara, don Javier Solana, ministro de Cultura, don Fernando Ledesma, ministro de Justicia (oculto), don José María Maravall, ministro de Educación y Ciencia, don Joaquín Leguina, presidente de la Comunidad de Madrid, don Manuel Gala, rector de la Universidad de Alcalá, don Julián Campos, ministro 
de Obras Públicas y Urbanismo, don Arsenio Lope Huerta, alcalde de Alcalá y don Carlos Molina del Pozo, secretario general de la Universidad.

Una característica muy importante de la negociación de ese convenio fue que en el transcurso de la misma se amplió, incluso, la ambición inicialmente planteada por el Ayuntamiento y la Universidad, cuando alguno de los socios solicitó contraprestaciones que iban a ser, de hecho, nuevas oportunidades para Alcalá. Las dos más transcendentales fueron, sin duda, las de la Dirección General del Libro, con el fin de obtener de la Universidad terrenos para construir la "Biblioteca Nacional de Préstamos" y el compromiso de apertura de una "Escuela Universitaria de Biblioteconomía y Archivística". De hecho, estas dos ideas del entonces director general don Jaime Salinas podían significar en un futuro inmediato la definición de Alcalá como uno de los dos grandes centros documentales y archivísticos de España, dada la existencia en la ciudad de uno de los grandes archivos del Estado (el Archivo General de la Administración). Y, sobre todo, la Universidad y la ciudad se verían extraordinariamente favorecidas Nota25 de VA con la instalación de la nueva Biblioteca Nacional, precisamente en el campusuniversitario NOTA46.

El convenio, por otra parte, no olvidaba que la Universidad de Alcalá se encuentra "a caballo" entre dos Comunidades Autónomas y, por tanto, su ímpetu restaurador y de dotación universitaria se extendía también a la ciudad de Guadalajara. 


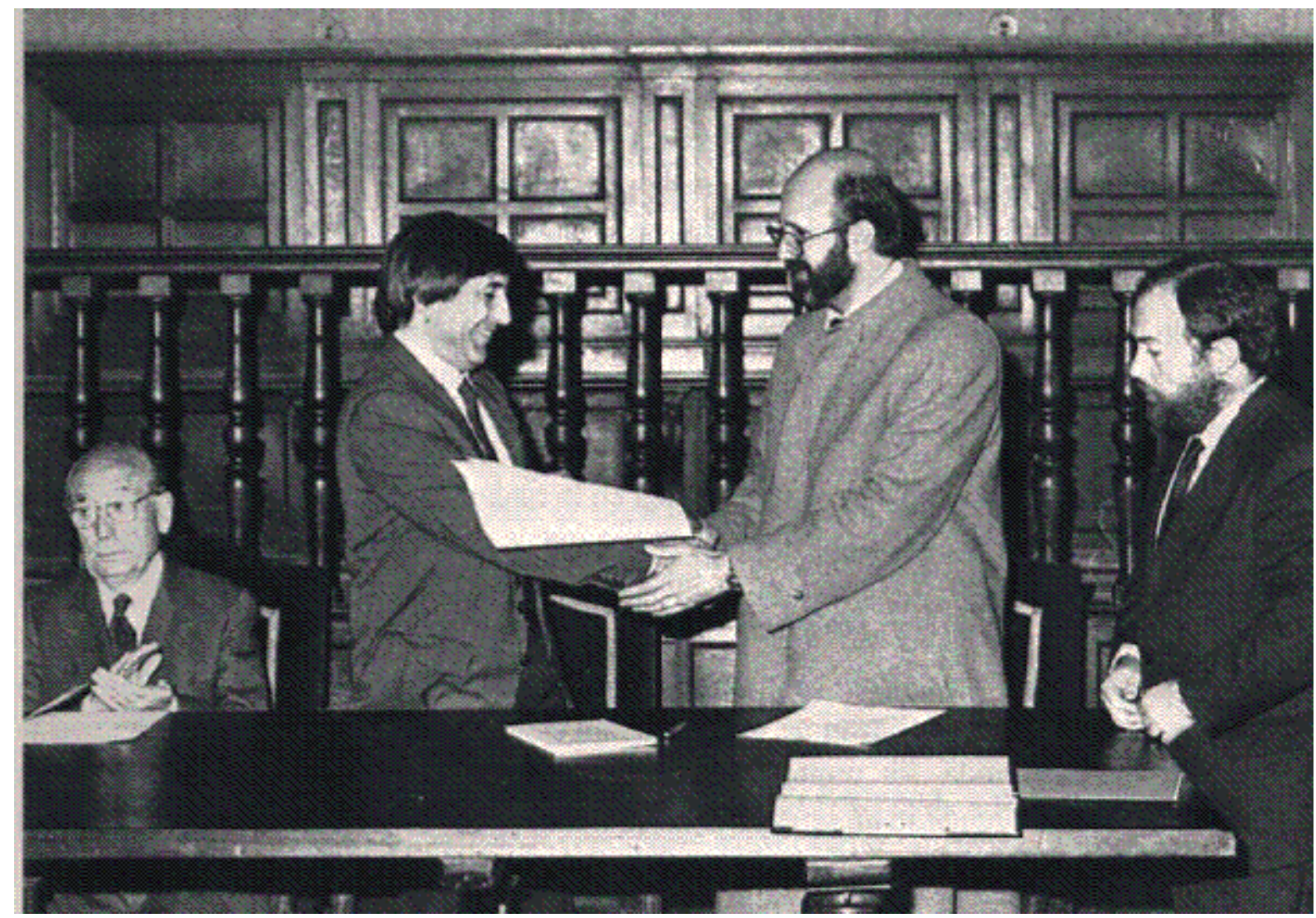

Firma del convenio Universidad-Ayuntamiento de Alcalá. En la foto, el rector y el alcalde de Alcalá junto con don Enrique Tierno Galván, alcalde de Madrid, y el secretario general de la Universidad, don Carlos Molina del Pozo.

Es de destacar también que a las actuaciones a llevar a cabo se les marcaban unos plazos (importantes en España, con una Administración tan poco flexible no tanto por la esperanza de cumplimiento, sino porque expresaban un compromiso de planificación de las inversiones) y, sobre todo, se constituían unos órganos muy definidos de coordinación (presidida por la Consejería de Educación de la Comunidad de Madrid), atípicos hasta ese momento en España, y de ejecución técnica (la "Oficina Técnica"), dependientes de la Universidad y de un ministerio de amplia capacidad en ese campo y también en lo económico como es el Ministerio de Obras Públicas.

El "Convenio de Alcalá" no es importante tan sólo porque sea un catálogo de compromisos concretos de restauración del patrimonio histórico de Alcalá y porque se haga con la principal finalidad de recuperar ésta como ciudad universitaria y 
cultural, sino también porque se perfiló en él un determinado tipo de universidad, enlazando, por tanto, con la particular "estructuración interna" a la que nos referimos en páginas anteriores.

CONTINUARÁ...

En el próximo número: El modelo de Universidad para Alcalá

LOS CONVENIOS

NOTAS

NOTA 39: LOPE HUERTA A.: "Universidad de Alcalá hacia el tercer despojo", Puerta de Madrid, 22 de octubre de 1979.

NOTA 40: Ver artículos citados en nota 36.

NOTA 41: Artículos 200 y 202 de los Estatutos.

NOTA 42: Don Manuel Gala fue reelegido rector en 1986, una vez terminado el proceso constituyente, para un periodo de cuatro años.

NOTA 43: En este ambiente se encuadran algunas de las acciones sobre Alcalá, como el estudio ya citado de la Dirección General de Arquitectura y el Apoyo de la Comunidad Autónoma al P.U.Y.S.A. También la Escuela de Arquitectura de Madrid empezaba a considerar a Alcalá como lugar de operaciones para las prácticas de unos alumnos cada vez más interesados en la rehabilitación de edificios. El Ayuntamiento y un poco más adelante la Universidad entrarían también en el programa de 
"Escuelas Taller", en las que se han unido muy eficazmente los tres principios de dar trabajo, formar a una mano de obra inexistente y recuperar nuestro patrimonio.

NOTA 44: El texto será reproducido en el apéndice núm. 1, que aparecerá en la próxima entrega.

NOTA 45: El convenio, del que tuve el honor de ser el redactor del primer borrador como vicerrector de infraestructura de la Universidad de Alcalá, sería llamado desde entonces "El Convenio de Alcalá". Véase el apéndice núm. 2 que aparecerá en la próxima entrega.

NOTA 46: Con el tiempo, el proyecto de "Biblioteca Nacional de Préstamos" se ha reconvertido en "Segundo Depósito de la Biblioteca Nacional", algo menos ambicioso que el primitivo, pero implicará su apertura con 2,5 millones de volúmenes. Por tan trascendental decisión para la Universidad de Alcalá ésta premió con su medalla de oro a don Jaime Salinas el 17 de noviembre de 1989, día de la "Annua Conmemoratio Cisneriana".

NOTA 24 DE VIVAT ACADEMIA: Las necesidades estaban muy claras y, aún hoy, algunas de ellas todavía son necesidades, no habiéndose hecho nada para paliarlas. Por ejemplo, en la actualidad se están utilizando fondos de la Comunidad Europea, destinados a infraestructura de investigación, para construir y recuperar edificios no orientados a tal fin.

NOTA 25 DE VIVAT ACADEMIA: Ninguna de las dos ideas se puso en marcha en las condiciones iniciales. Ya desde el principio, a pesar de que se siguió manteniendo el espejismo frente a la comunidad universitaria, la Biblioteca Nacional y la Dirección General del Libro hablaban de "segundo depósito" y no de la tan ambicionada "Biblioteca Central de Préstamos". De hecho este segundo depósito, que no ha 
beneficiado en nada a nuestra universidad, más bien al contrario, se pretendió instalarlo en San Lorenzo de El Escorial, puesto que no necesitaba de, ni ayudaba a, ningún entorno universitario. 